\title{
Estimation of the Humerus Length by its Proximal Segments: A South Indian Anatomical Study
}

\author{
Kasargod Umesh Prashanth ${ }^{1}$ Mangala Manohar Pai ${ }^{2}$ Bukkambudhi Virupakshamurthy Murlimanju ${ }^{2}$ \\ Latha Venkatraya Prabhu ${ }^{2}$ Manoor Dass Prameela ${ }^{2}$ \\ ${ }^{1}$ Department of Anatomy, A.J. Institute of Medical Sciences and \\ Research, Kuntikana, Mangalore, India \\ 2 Department of Anatomy, Kasturba Medical College, Manipal \\ Academy of Higher Education, Karnataka, India \\ Address for correspondence Mangala Manohar Pai, MBBS, MD, \\ Department of Anatomy, Kasturba Medical College, Manipal Academy \\ of Higher Education, Centre for Basic Sciences, Bejai, Mangalore, \\ 575004, Karnataka, India (e-mail: mangala.pai@manipal.edu).
}

J Morphol Sci 2019;36:67-71.

\begin{abstract}
Keywords

- archeology

- forensic medicine

- humerus

Introduction To determine the morphometric data of the proximal segments of the humerus in the South Indian population, and to obtain the regression equations that will enable us to predict the whole length of humerus.

Materials and Methods The present study included 166 dried adult human humeri. Their lengths were measured by using the osteometric board. The seven proximal segment lengths of the humeri were assessed by using a digital Vernier caliper (Mitutoyo Corporation 150 mm/6 inch, model number 500-196-20, Kawasaki, Japan). Results The mean humerus length in the present study was $30.75 \pm 2.03 \mathrm{~cm}$ on the right side and $30.27 \pm 2.28 \mathrm{~cm}$ on the left side. The comparison between the right and left sides of the proximal segments of the humerus did not yield statistically significant results $(p>0.05)$. The present study observed that the relationship between the dimensions of the proximal segments of the humerus and the length of humerus were strong $(p=0.00)$. The oblique length between the most proximal and distal points over the anatomical neck was the best parameter to predict the length of humerus (the Pearson coefficient was 0.78 for the right side and 0.77 for the left side).

Conclusion The simple regression formulae, which were derived in this study, are helpful in the estimation of the length of the humerus. The formulae can be used in forensic investigations, in which the stature of a person has to be determined and only bone fragments are available. The morphometric data of the present study have implications in archaeological and anthropological studies. The data are enlightening to orthopedicians, when planning reconstructive surgeries of the proximal end of the humerus in the South Indian population.
\end{abstract}

\section{Introduction}

Identity is considered an important aspect in anthropology, forensic science and social demography. The stature is believed to be an integral part of identity. However, estimation of the identity of body parts and the stature of a person is complex, indeed. In archeology, the stature estimation of human skeletal remains is an essential step in assessing the general body size, health and sexual dimorphism. ${ }^{1,2}$ However, variation exists among the intra- and interpopulation, as well as between the male and female individuals. ${ }^{3,4}$ The ethnic, ancestral and geographical differences exist because of the hereditary, environmental and social factors. Krishan ${ }^{5}$ reported that the stature of an individual is the variable that can be estimated with the greatest accuracy, even from the smallest bone available. However, long bones received

August 2, 2018

accepted

February 15, 2019
DOI https://doi.org/

10.1055/s-0039-1685223. ISSN 2177-0298.
Copyright $(2019$ by Thieme Revinter

Publicações Ltda, Rio de Janeiro, Brazil
License terms

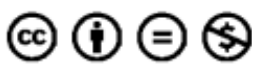


are preferred for stature determination because of their better accuracy. ${ }^{5}$

Steele ${ }^{6}$ described that estimation of living stature can be done by using the humeral length in the absence of more accurate long bones, such as the femur or tibia. Salles et al. ${ }^{7}$ opined that the forensic analysis of the modern population cannot be based on the formulas that were obtained from the ancient population. This is because of the rapid diachronic secular changes of limbs, and it has been observed by Salles et al. $^{7}$ that human beings are growing taller. In this context, developing a set of morphometric data from the modern population is considered to be essential to forensic investigations. There are several methods that can be used to estimate the stature of an individual by using his bones, among which the most reliable one is the regression analysis. ${ }^{8,9}$ Regression analysis is more appropriate in defining the relationship between the length of long bone and living stature of an individual, as well as the relationship between the measurements of bone fragments and bone length. ${ }^{9}$ The present study to collect the dimensions of the proximal segments of the humerus in the South Indian population and to obtain the regression equations that will enable us to predict the whole length of humerus.

\section{Materials and Methods}

The present study included 166 (82 right sided and 84 left sided) dried adult human cadaveric humeri, which were obtained from the collections of anatomy and forensic medicine departments of Kasturba Medical College, Mangalore, India. The humeri were carefully observed with respect to the proximal segments, which are vital in this present study. The humeri that presented significant deformities at the proximal end were excluded from the present study. The gender and age determination of the humeri were not performed in the present study. The present study was approved by the TimeBound Research Ethics Committee of Kasturba Medical College, Mangalore (A Constituent Unit of Manipal Academy of Higher Education, Manipal, Karnataka, India) on July 28, 2010. The same researcher performed all the measurements, which prevented inter observer variation. Each measurement was performed three times and the average was calculated.

The maximum length of humerus (MLH) was measured by using the osteometric board. This was the maximum distance between the most proximal points over the caput humeri and the most distal point of the trochlea. The measurements of the proximal segments of the humeri were performed by using a digital Vernier caliper (Mitutoyo Corporation $150 \mathrm{~mm} / 6$ inch, model number 500-196-20, Kawasaki, Japan) (-Fig. 1).

S1 - distance between the most proximal part of the head of the humerus and the most distal part of the anatomical neck

S2 - oblique length between the most proximal and distal points in the anatomical neck

S3-distance between the most medial aspects of the lesser tubercle and the most lateral aspect of the greater tubercle S4 - horizontal breadth of the humeral head, at its center S5 - largest breadth of the greater tubercle

S6 - largest breadth of the lesser tubercle

S7 - the widest part of the proximal end of the humerus

The morphometric data were tabulated separately for the right and left sides of the humeri. The data were statistically analyzed by using the SPSS software, version 15 (SPSS Inc., Chicago, IL, USA). After obtaining the mean and standard
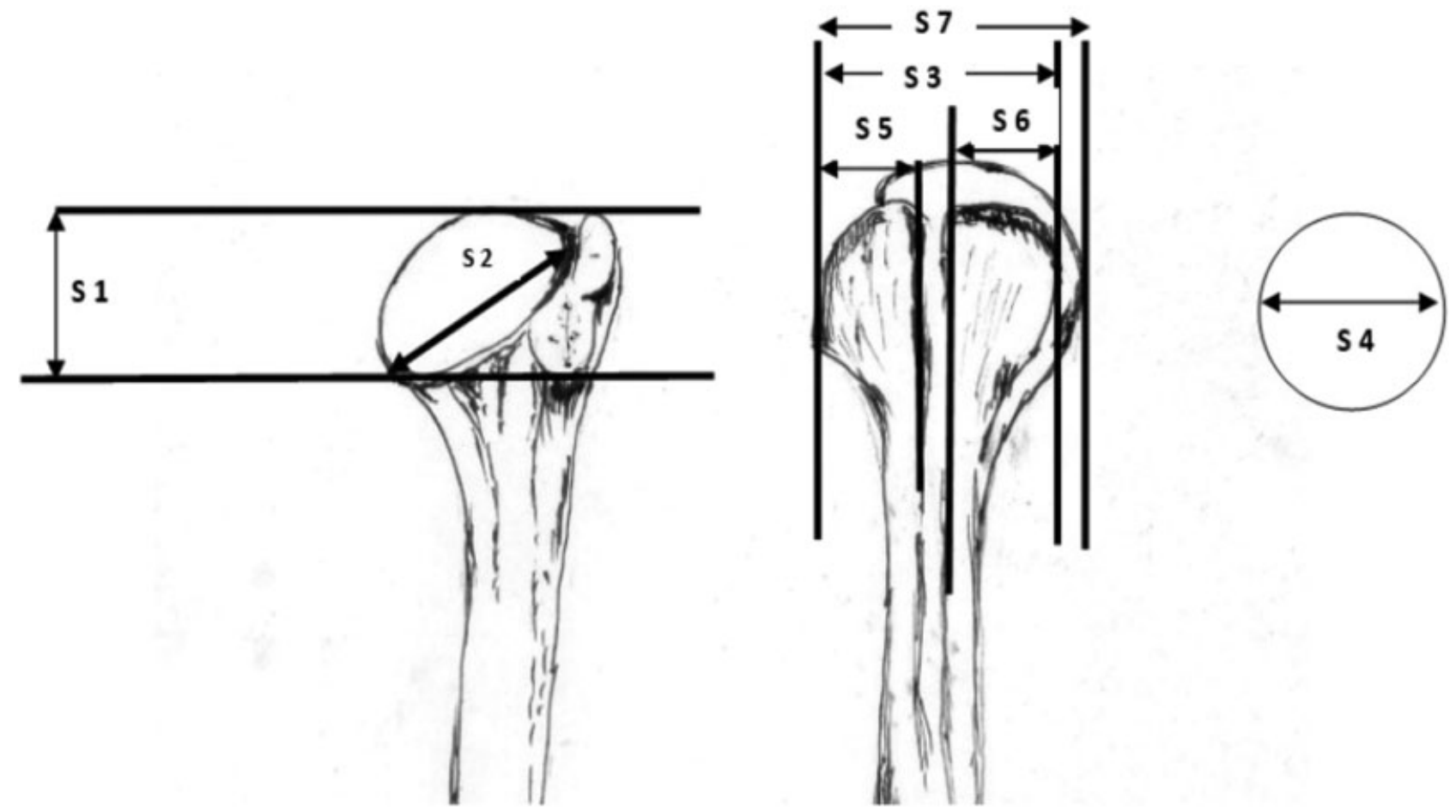

Fig. 1 Measurements of the proximal segments of the humerus performed in the present study. 
Table 1 Morphometric data of the proximal segments of the humerus $(n=166)$

\begin{tabular}{|l|l|l|l|}
\hline Segment & $\begin{array}{l}\text { Right side } \\
(\boldsymbol{n}=\mathbf{8 2})\end{array}$ & $\begin{array}{l}\text { Left side } \\
(\boldsymbol{n}=\mathbf{8 4})\end{array}$ & $P$-value \\
\hline S1 & $3.28 \pm 0.31$ & $3.25 \pm 0.32$ & 0.43 \\
\hline S2 & $4.12 \pm 0.36$ & $4.08 \pm 0.35$ & 0.45 \\
\hline S3 & $3.26 \pm 0.47$ & $3.29 \pm 0.40$ & 0.72 \\
\hline S4 & $3.84 \pm 0.31$ & $3.80 \pm 0.35$ & 0.46 \\
\hline S5 & $2.92 \pm 0.29$ & $2.84 \pm 0.27$ & 0.08 \\
\hline S6 & $1.36 \pm 0.17$ & $1.36 \pm 0.19$ & 0.78 \\
\hline S7 & $4.50 \pm 0.36$ & $4.42 \pm 0.37$ & 0.16 \\
\hline
\end{tabular}

(values are given in $\mathrm{cm}$, mean $\pm \mathrm{SD}$, independent samples test)

deviation (SD.) for each of the parameters, the association between the variables and the length of the humerus was investigated by means of the Pearson correlation coefficient (r). The linear regression was applied for the right and left humeri separately. The simple linear regression shows the regression coefficient (COE) and the significance ( $p$-value) for the dimensions of the proximal segments of the right and left humeri, separately. The simple linear regression analysis shows the relationship of the dimensions of the individual proximal segment with the MLH. This analysis shows the coefficient of correlation (Pearson correlation coefficient) between a dependent variable and an independent variable. The Pearson coefficient determines the strength of the relationship between the variables. The $p$-value determines the statistical significance. A $p$-value $<0.05$ was considered statistically significant. The simple linear regression equations were formulated from the obtained data, which would predict the mean length of the humerus (MHL).

\section{Results}

From the 166 humeri ( 82 of right side and 84 of left side), the MHL on the right side was $30.75 \mathrm{~cm}$, with a SD of $2.03 \mathrm{~cm}$. The MHL on the left side was $30.27 \mathrm{~cm}$, with a SD of $2.28 \mathrm{~cm}$.

The descriptive statistics represented in - Table 1 shows the mean values of the proximal segments of the humeri of both the sides. The data were compared by using, independent samples test. The analysis showed that the comparison between the right and left sides was not statistically significant. The 2-tailed $p$-values were higher than $0.05(p>0.05)$.

The Pearson coefficient dictates the quantitative relation of each of the segment with the length of humerus. The Pearson coefficient, coefficient of determination $\left(\mathrm{R}^{2}\right)$ and $p$-values obtained in the present study are given in -Table 2 . The present study observed that the relationship between the dimensions of the proximal segments of the humerus and the length of the humerus were proportional. The relationship was real and did not occur by chance ( $p=0.00$, which is statistically highly significant).

- Table 3 shows the Pearson coefficient in decreasing order of values. Among all the measurements performed, the S2 segment of both sides was the best parameter. The Pearson coefficient was 0.78 on the right side and 0.77 on the left side. The second best parameter was the $\mathrm{S7}$ segment (The Pearson coefficient was 0.77 on both the sides). The lowest Pearson coefficient value was for the S6 segment on the right side, which was 0.38 , and on the left side, it was for the S3 segment, which was 0.41 .

The simple regression was formulated, $\mathrm{Y}=(\mathrm{a}+\mathrm{bX}) \pm \mathrm{SD}$, in which $Y$ is the maximum humeral length (dependent variable); $X$ is the dimension of the proximal segment of the humerus (independent variable), $b$ is the multiplying factor and $a$ is the constant, which was obtained by using the SPSS software (SPSS Inc.). The simple regression formula, which has highest multiplying factor, is considered to be the best. The simple regression formulae, which were obtained in the present study are given in - Table 4 . The formula applied to the S4 segment was the best for predicting the length of humerus on the right side (the multiplying factor was 4.67). On the left side, the formula that was applied to the 55 segment was considered the best (the multiplying factor was 6.19).

\section{Discussion}

In the absence of the cranium and the pelvis, the fragments of long bones can be used during the anthropology and forensic science investigations. ${ }^{10-12}$ The simple regression formulae are considered important during the determination of the stature from the available anthropometric dimensions. ${ }^{13,14}$ Singhal and Rao ${ }^{15}$ reported that the length of the humerus can be used to estimate the stature of an individual with an error margin of less than $2 \mathrm{~cm}$. They also reported that their

Table 2 Pearson coefficient and $p$-values of the right $(n=82)$ and left $(n=84)$ sides of the proximal humeral segments

\begin{tabular}{|l|l|l|l|l|l|l|}
\hline \multirow{2}{*}{ Segment } & \multicolumn{2}{l|}{ Pearson coefficient } & \multicolumn{2}{l|}{$\mathrm{R}^{2}$} & \multicolumn{2}{l|}{ Significance ( $p$-value) } \\
\cline { 2 - 7 } & Right side & Left side & Right side & Left side & Right side & Left side \\
\hline S1 & 0.54 & 0.50 & 0.30 & 0.25 & 0.00 & 0.00 \\
\hline S2 & 0.78 & 0.77 & 0.62 & 0.59 & 0.00 & 0.00 \\
\hline S3 & 0.39 & 0.41 & 0.15 & 0.17 & 0.00 & 0.00 \\
\hline S4 & 0.71 & 0.72 & 0.50 & 0.51 & 0.00 & 0.00 \\
\hline S5 & 0.63 & 0.73 & 0.40 & 0.53 & 0.00 & 0.00 \\
\hline S6 & 0.38 & 0.46 & 0.15 & 0.21 & 0.00 & 0.00 \\
\hline S7 & 0.77 & 0.77 & 0.60 & 0.59 & 0.00 & 0.00 \\
\hline
\end{tabular}


Table 3 Pearson coefficient of the proximal segments in decreasing order

\begin{tabular}{|l|l|l|l|l|l|}
\hline Right humerus & Pearson coefficient & $P$-value & Left humerus & Pearson coefficient & $P$-value \\
\hline S2 & 0.78 & 0.00 & S2 & 0.77 & 0.00 \\
\hline S7 & 0.77 & 0.00 & S7 & 0.77 & 0.00 \\
\hline S4 & 0.71 & 0.00 & S5 & 0.73 & 0.00 \\
\hline S5 & 0.63 & 0.00 & S4 & 0.72 & 0.00 \\
\hline S1 & 0.54 & 0.00 & S1 & 0.50 & 0.00 \\
\hline S3 & 0.39 & 0.00 & S6 & 0.46 & 0.00 \\
\hline S6 & 0.38 & 0.00 & S3 & 0.41 & 0.00 \\
\hline
\end{tabular}

Table 4 Simple regression formulae to determine the mean humeral length (MHL) from the data of the proximal segments

\begin{tabular}{|l|l|}
\hline Right humerus & Left humerus \\
\hline $\mathrm{MHL}=19.06+3.55$ & $\mathrm{MHL}=18.60+3.60$ \\
$(\mathrm{~S} 1) \pm 1.71$ & $(\mathrm{~S} 1) \pm 1.98$ \\
\hline $\mathrm{MHL}=12.35+4.46$ & $\mathrm{MHL}=9.89+5.00$ \\
$(\mathrm{~S} 2) \pm 1.26$ & $(\mathrm{~S} 2) \pm 1.47$ \\
\hline $\mathrm{MHL}=25.28+1.67$ & $\mathrm{MHL}=22.62+2.33$ \\
$(\mathrm{~S} 3) \pm 1.88$ & $(\mathrm{~S} 3) \pm 2.09$ \\
\hline $\mathrm{MHL}=12.84+4.67$ & $\mathrm{MHL}=12.32+4.73$ \\
$(\mathrm{~S} 4) \pm 1.44$ & $(\mathrm{~S} 4) \pm 1.60$ \\
\hline $\mathrm{MHL}=18.06+4.35$ & $\mathrm{MHL}=12.68+6.19$ \\
$(\mathrm{~S} 5) \pm 1.58$ & $(\mathrm{~S} 5) \pm 1.56$ \\
\hline $\mathrm{MHL}=24.57+4.55$ & $\mathrm{MHL}=22.78+5.55$ \\
$(\mathrm{~S} 6) \pm 1.89$ & $(\mathrm{~S} 6) \pm 2.03$ \\
\hline $\mathrm{MHL}=11.13+4.36$ & $\mathrm{MHL}=9.27+4.75$ \\
$(\mathrm{~S} 7) \pm 1.30$ & $(\mathrm{~S} 7) \pm 1.47$ \\
\hline
\end{tabular}

regression formula, which was derived from the longer segments of the humerus, can be used with other samples of the Indian population. However, if there are shorter segments, new equations are required. Somesh et al $^{16}$ studied the distance between the most proximal point of the humeral head and the greater tuberosity. They also determined the distance between the head of the humerus and the surgical neck of the humerus in the South Indian population. The present study did not measure these segments of the humerus. The best parameters in the present study were, the oblique length between the most proximal and the most distal points on the anatomical neck (S2), the horizontal breadth of the humeral head at its center (S4), and the widest part of the proximal end of the humerus (S7). These horizontal dimensions are different from the ones reported by Somesh et al, ${ }^{16}$ who measured the vertical segments, which had lower coefficient values. This suggests that the horizontal segments of the present study gave better results. Salles et $\mathrm{al}^{7}$ also reported that the oblique length between the most proximal and the most distal points on the anatomical neck, and the horizontal breadth of the humeral head at its center had good correlation to the MLH.

The forensic, anthropologic and archaeological studies suggest that the MHL offers important data to study the characteristics of a population. ${ }^{17}$ In the present South Indian study, the MHL was $30.75 \pm 2.03 \mathrm{~cm}$ on the right side and $30.27 \pm 2.28 \mathrm{~cm}$ on the left side, respectively. These data are almost similar to the data from the Turkish population. ${ }^{18}$ However, the MHL of the present study was lower in comparison to that of other European population. This is due to the ancestral variation, as the Europeans are tall and robust. ${ }^{13,19}$ In a Brazilian study, the oblique length between the most proximal and the most distal points on the anatomical neck were $4.9 \pm 0.5 \mathrm{~cm}$ and $4.8 \pm 0.4 \mathrm{~cm}$ for the right and left sides, respectively. ${ }^{7}$ These dimensions are much higher than the ones obtained in the present study, which were $4.12 \pm 0.36 \mathrm{~cm}$ and $4.08 \pm 0.35 \mathrm{~cm}$, respectively. However, the horizontal breadth of the humeral head at its center was $3.84 \pm 0.31 \mathrm{~cm}$ for the right side and $3.8 \pm 0.35 \mathrm{~cm}$ for the left side, in the present study. This is similar to the data observed in the Brazilian study by Salles et al, which was $4.0 \pm 0.4 \mathrm{~cm}$ and $3.9 \pm 0.3 \mathrm{~cm}$, respectively. ${ }^{7}$

By using the derived regression formulae, one can fairly estimate the full length of humerus. This is useful when only a few segments of a long bone are available. By using the $\mathrm{MLH}$, it is possible to determine the stature of an individual. In the present study, the correlation between the measurements of the proximal segments of the humerus and the stature of an individual was not possible, due to lack of information about the dried bones. The stature of an individual is extremely variable and can be affected by ethnic differences. The regression formula of one population cannot be applied to another. ${ }^{16}$ In this context, the data and formulae of the present study are important as they provide data about the South Indian population. The morphometric data of the humeral segments have implications in the identification of missing persons during the medico-legal investigations. ${ }^{17,20}$ The morphometric data of the humerus segments are enlightening to orthopedic surgeons during the treatment of humeral fractures and reconstruction of the humerus. ${ }^{16}$ The data are also enlightening during procedures like prosthetic designing, sizing and positioning. ${ }^{21,22}$

\section{Conclusions}

We believe that the data in the present study will contribute to estimation of the humeral length and the length of its proximal segments in a subset of the South Indian population. The derived formulae of the present study may be useful in forensic investigations in which the stature of an 
individual has to be determined and there are only few segments of bone are available. The data can be of help in archaeological and anthropological studies in which excavations often yield only a few incomplete skeletal remains. The data in the present study are also essential to orthopedicians, who can utilize them during the planning of reconstructive surgeries involving the proximal end of the humerus.

\section{Note}

Mangala M. Pai is presently working as Professor and Head of the Anatomy Department and is interested in the field of human morphology. She has more than 50 research articles published on human morphology and anthropology.

\section{Sources of Support}

None.

\section{Conflicts of Interest}

The authors declare that they have no conflicts of interest.

\section{References}

1 Hoppa RD, Gruspier KL. Estimating diaphyseal length from fragmentary subadult skeletal remains: implications for palaeodemographic reconstructions of a southern Ontario ossuary. Am J Phys Anthropol 1996;100(03):341-354

2 Raxter MH, Auerbach BM, Ruff CB. Revision of the Fully technique for estimating statures. Am J Phys Anthropol 2006;130(03): 374-384

3 Pearson OM. Activity, climate, and postcranial robusticity: implications for modern human origins and scenarios of adaptive change. Curr Anthropol 2000;41(04):569-607

4 Ruff CB. Body size, body shape, and long bone strength in modern humans. J Hum Evol 2000;38(02):269-290

5 Krishan K. Anthropometry in forensic medicine and forensic science - 'forensic anthropometry'. The Internet Journal of Forensic Science 2006;2:1

6 Steele DG. Estimation of stature from fragments of long limb bones. In: Stewart TD, ed. Personal Identification in Mass
Disaster. Washington, D.C.: Smithsonian Institution Press; 1970: 85-97

7 Salles AD, Carvalho CRF, Silva DM, Santana LA. Reconstruction of humeral length from measurements of its proximal and distal fragments. Braz J Morphol Sci 2009;26:55-61

8 Işcan MY. Global forensic anthropology in the 21st century. Forensic Sci Int 2001;117(1-2):1-6

9 Iscan MY. Forensic anthropology of sex and body size. Forensic Sci Int 2005;147:107-112

10 Beddoe J. On the stature of the older races of England, as estimated from the long bones. J Anthropol Inst G B Irel 1888; 17:201-209

11 Nath S, Badkur P. Reconstruction of stature from long bone lengths. Anthropologist 2002;4:109-114

12 Petersen HC. On the accuracy of estimating living stature from skeletal length in the grave and by linear regression. Int J Osteoarchaeol 2005;15:106-114

13 Willey P, Falsetti T. Inaccuracy of height information on driver's licenses. J Forensic Sci 1991;36(03):813-819

14 Williams PL, Warwick R, Dyson M, Bannister LH. The humerus. In: Gray's Anatomy. 37th ed,. Edinburgh: Churchill Livingstone; 1989:406

15 Singhal S, Rao V. Estimation of total length of humerus from its segments. Med Sci Law 2011;51(01):18-20

16 Somesh MS, Prabhu LV, Pai MM, Shilpa K, Krishnamurthy A, Murlimanju BV. Morphometric study of the humerus in Indian population. Int J Morphol 2011;29:1174-1180

17 Wright LE, Vásquez MA. Estimating the length of incomplete long bones: forensic standards from Guatemala. Am J Phys Anthropol 2003;120(03):233-251

18 Muñoz JI, Liñares-Iglesias M, Suárez-Peñaranda JM, et al. Stature estimation from radiographically determined long bone length in a Spanish population sample. J Forensic Sci 2001;46(02):363-366

19 Zverev Y, Chisi J. Estimating height from arm span measurement in Malawian children. Coll Antropol 2005;29(02):469-473

20 Ross AH, Konigsberg LW. New formulae for estimating stature in the Balkans. J Forensic Sci 2002;47(01):165-167

21 Murlimanju BV, Prabhu LV, Pai MM, et al. Anthropometric study of the bicipital groove in Indians and its clinical implications. Chang Gung Med J 2012;35(02):155-159

22 Robertson DD, Yuan J, Bigliani LU, Flatow EL, Yamaguchi K. Threedimensional analysis of the proximal part of the humerus: relevance to arthroplasty. J Bone Joint Surg Am 2000;82-A(11):1594-1602 